\title{
Problemas e estratégias de gestão do SUS: a vulnerabilidade dos municípios de pequeno porte
}

\author{
Management problems and strategies: The vulnerability \\ of small-sized municipalities
}

Elisangela Pinafo (https://orcid.org/0000-0002-7553-7588) ${ }^{1}$

Elisabete de Fátima Polo de Almeida Nunes (https://orcid.org/0000-0002-5873-7561) ${ }^{1}$

Brígida Gimenez Carvalho (https://orcid.org/0000-0003-3850-870X) ${ }^{1}$

Fernanda de Freitas Mendonça (https://orcid.org/0000-0002-3532-5070) ${ }^{1}$

Carolina Milena Domingos (https://orcid.org/0000-0002-7725-1831) ${ }^{1}$

Camila Ribeiro Silva (https://orcid.org/0000-0001-9297-4838) ${ }^{1}$

${ }^{1}$ Programa de PósGraduação em Saúde Coletiva, Universidade Estadual de Londrina. Av. Robert koch 60, Vila Operária. 86039-440 Londrina PR Brasil. elisangelapinafo@ uenp.edu.br

\begin{abstract}
The decentralization process has a strong impact on the finances of small-sized municipalities (SSMs), which are the most vulnerable entity of the Federative Republic of Brazil. This paper aims to analyze the main problems and management strategies used by SSMs to address the inequalities resulting from the decentralization process. This qualitative research is developed through operative groups with 55 workers from the management teams of SSMs in the northern macroregion of Paraná. A comprehensive and interpretative analysis was conducted using the Social Game Theory as a theoretical reference. Among the problems examined are the insufficient capacity to manage municipalities and provide comprehensive health care to citizens. The formation of Intermunicipal Health Consortia, the purchase of services through parallel contracts with private providers, and the adhesion to state and federal programs are strategies to address the problems, but they trigger problems of their own. To minimize the vulnerability of SSMs, it is necessary to empower the municipal manager, implement processes of listening to the SSMs, and foster a culture of facing problems in a collective and shared way among the federated entities to create interfederative management.

Key words Decentralization, Health management, Public Health System, Small-sized municipalities
\end{abstract}

Resumo O processo de descentralização exerce forte impacto nas finanças dos Municípios de Pequeno Porte (MPP) e estes são o ente mais vulnerável da federação. Objetivou-se analisar os principais problemas e as estratégias de gestão utilizadas pelos MPP para enfrentar as desigualdades decorrentes do processo de descentralização. Pesquisa qualitativa desenvolvida por meio de grupos operativos com 55 trabalhadores das equipes gestoras de MPP da macrorregião norte do Paraná. Foi realizada análise compreensiva e interpretativa utilizando a Teoria do Jogo Social como referencial teórico. Dentre os problemas, estão a insuficiente capacidade para fazer a gestão dos municípios e para ofertar atenção integral à saúde aos munícipes. A constituição de Consórcios Intermunicipais de Saúde, a compra de serviços por contratos paralelos com prestadores privados e a adesão a programas do estado e da União são estratégias para o enfrentamento dos problemas, porém estas desencadeiam um intercâmbio de problemas. Para minimizar a vulnerabilidade dos MPP, é preciso fomentar o empoderamento do gestor municipal, implantar processos de escuta dos MPP e de uma cultura de enfrentamento dos problemas de forma coletiva e compartilhada entre os entes federados, para que haja uma gestão interfederativa.

Palavras-chave Descentralização, Gestão em saúde, Sistema Único de Saúde, Municípios de pequeno porte 


\section{Introdução}

A maioria municípios brasileiros são de pequeno porte, muitos deles criados após a Constituição Federal (CF) de 1988. Com a CF os municípios se tornaram entes federados com autonomia política e tributária, e foram favorecidos com a repartição de recursos por meio das transferências intergovernamentais ${ }^{1}$.

Os municípios de pequeno porte (MPP), ou seja, aqueles com população inferior a 20 mil habitantes, apesar de representarem cerca de 70\% dos municípios do país, são o ente mais vulnerável da federação. A maioria destes municípios alia: condições limitadas, tanto de ofertas de serviços de saúde, como de capacidade de gestão, para responder sobre as políticas públicas que lhes foram atribuídas com o processo de descentralização ${ }^{2}$; pouca autonomia para a gestão dos orçamentos municipais ${ }^{3}$; menor capacidade de arrecadação fiscal e consequentemente menor alocação de recursos orçamentários ${ }^{1,4}$; poder limitado de decisão dos gestores municipais nos espaços de governança ${ }^{5}$ e, ainda, dificuldade de fixação de profissionais médicos ${ }^{6}$.

Além disso, com a criação do Sistema Único de Saúde (SUS), em 1988, houve a descentralização político-administrativa, transferindo, especialmente aos municípios, responsabilidades referentes à gestão de ações e serviços de saúde. Essa é uma função complexa, seja pela interferência dos determinantes sociais e epidemiológicos no processo de adoecimento da população, seja por aspectos técnicos, políticos e econômicos ${ }^{7}$.

Em MPP, o gestor do SUS além de ser responsável pela Atenção Básica ( $\mathrm{AB}$ ) aos seus munícipes, também necessita viabilizar, por meio de pactuações com demais gestores municipais e estaduais e da contratação de serviços privados ${ }^{5}$, o acesso de sua população aos demais níveis de atenção, no intuito de oferecer atendimento integral à sua população, mesmo que esse não ocorra em seus limites territoriais ${ }^{8,9}$. Neste sentido, depara-se com a tarefa de gerir uma rede de serviços heterogênea e não integrada institucionalmente, e com oferta insuficiente de serviços na Média e Alta Complexidade (MAC) ${ }^{10}$.

Nesse contexto, a análise apresentada por Teixeira et al. ${ }^{11}$ é de que, apesar de os municípios terem sido beneficiados no processo de descentralização, com a repartição de recursos, eles ainda continuam apresentando uma grande vulnerabilidade fiscal. Se por um lado, aumentaram suas fontes de recursos, por outro, o processo de descentralização das funções públicas exercem forte impacto em suas finanças. Diante disso, as implicações advindas do processo de descentralização impactaram nesses municípios de uma forma bem desigual se comparadas aos de maior porte.

Considerando o panorama vivenciado pelos MPP, questiona-se: Quais são os problemas enfrentados pela equipe gestora no âmbito da gestão municipal da saúde? Quais estratégias de gestão são utilizadas para o enfrentamento desses problemas?

Apesar da relevância desta temática, a produção científica sobre a dinâmica da gestão do SUS em MPP, com a análise dos problemas e das estratégias de gestão utilizadas, é escassa ${ }^{12,13}$. Nesse sentido, o objetivo do estudo foi analisar os principais problemas e as estratégias de gestão utilizadas pelos MPP para enfrentar as desigualdades decorrentes do processo de descentralização, à luz da teoria do Jogo Social, de Carlos Matus.

\section{Referencial teórico metodológico}

Para Carlos Matus, o sistema social é um grande jogo, complexo, nebuloso, composto de vários outros jogos individuais entrelaçados. Esses jogos são simultâneos e coexistem no mesmo tempo e espaço físico, possuem dinâmica própria, particularidades, e reproduzem em seu interior outros jogos de forma subordinada. O jogo social divide-se em lógicas de jogo superpostas, com uma intersecção dominante ${ }^{14}$.

$\mathrm{O}$ autor ${ }^{14}$ descreve a existência de nove jogos de poder: político, econômico, macroorganizacional, pessoal, da vida cotidiana, da natureza, da comunicação, dos valores e da ciência. Entretanto, os que se destacaram na análise do presente estudo, na gestão do SUS em MPP, foram os jogos político, econômico e macroorganizacional.

O jogo político, disputa e distribui o poder político, civil e militar, cuja função é criar, concentrar e distribuir o poder social. O jogo econômico tem a função de produzir bens e serviços demandados pela população para satisfazer suas necessidades, distribuir a renda, distribuir a propriedade de bens econômicos ${ }^{14}$. Por sua vez, o jogo macroorganizacional produz a ação organizacional, que é uma ação humana coletiva capaz de materializar a produção institucional a serviço de qualquer um dos outros jogos. É um jogo de luta pela distribuição de governança e de poder organizacional ${ }^{14}$.

Para Matus ${ }^{14}$, a vivência em sociedade faz emergir problemas que são comuns a qualquer tipo de prática social. Entretanto, a complexidade 
dos problemas sociais crescem em ritmo acelerado, enquanto a capacidade pessoal ou institucional para governar esses problemas fica cada vez mais distante de superá-los.

Os problemas sociais para Matus ${ }^{14}$ são, sobretudo, problemas quase-estruturados, pois são mais complexos, geralmente multicausais, nem sempre fáceis de serem todas as causas identificadas, e nem sempre têm propostas consensuais para sua solução. De modo que, ao tentar resolver os problemas, produz-se um intercâmbio destes, que beneficia algumas pessoas, mas, ao mesmo tempo, pode prejudicar outras. Para o autor, o problema depende do ponto de vista e do lugar ocupado pelo ator. Ele denomina "ator" a pessoa que vivencia o problema, e representa um papel.

A estratégia, por sua vez, é uma categoria do possível em função do necessário ${ }^{15}$. É um momento dedicado ao como fazer, onde se constroem caminhos para se atingir a imagem-objetivo, ciência de tornar possível, de reduzir as incertezas e acumular forças ${ }^{16}$. É a forma de lidar com os outros jogadores, diante de situações cujos objetivos e interesses são divergentes e as circunstâncias que cercam o jogo social tornam-se conflitantes ${ }^{17}$. Matus ${ }^{14}$ distingue três planos de caracterização de uma estratégia: o plano de sua administração, ou forma na direção interna do ator; o plano das vias escolhidas para lidar com o outro; e o plano do conteúdo do propósito, em relação ao interesse particular ou o interesse da coletividade social (Figura 1).

De acordo com sua forma, a estratégia pode ser aberta ou fechada. Ao analisar as possibilidades de meios estratégicos verifica-se que esses são numerosos. É possível seguir o caminho da imposição, da negociação, da persuasão, da coação, do julgamento em tribunais, da dissuasão, da confrontação e da guerra. Já a estratégia, por seu conteúdo e propósito, fica marcada por se privilegiar da ação de concertação ou da ação estratégica, dois tipos de ação que não são compatíveis entre $\mathrm{si}^{14,18}$.

Posto isto, compreende-se que os participantes do grande jogo social, neste caso do Sistema de Saúde, desenvolvem uma constante luta pelo poder, pois o poder é meio e fim e é gratificante ter sua posse ou usá-lo. Para alguns participantes, o poder como meio é mais gratificante que como fim. Essa luta pelo poder é canalizada por meio da competição pela supremacia de um dos jogos sobre os outros, ou pela competição pelo domínio em cada jogo ${ }^{14}$.

A área da gestão do SUS em MPP é permeada por problemas sociais oriundos das necessidades dos indivíduos e coletividade e que, de acordo com a análise da situação social e da realidade enfrentada pelo serviço de saúde, os atores sociais representados pela equipe gestora podem utilizar várias alternativas de solução e/ou estratégias de gestão para enfrentar esses problemas ${ }^{12}$.

No presente estudo os atores que interpretam esses problemas são os integrantes das equipes gestoras municipais, incluindo o secretário municipal de saúde. Cada qual, dentro de seu contexto social e realidade enfrentada, detêm um poder e possui um papel no jogo social da gestão do SUS, em busca do enfrentamento de problemas oriundos de necessidades individuais ou coletivas dos usuários desse sistema.

\section{Métodos}

Trata-se de uma pesquisa de natureza qualitativa desenvolvida com trabalhadores que compõem a equipe gestora de MPP da macrorregião norte do Paraná, da qual fazem parte a $16^{\mathrm{a}}, 17^{\mathrm{a}}, 18^{\mathrm{a}}, 19^{\mathrm{a}} \mathrm{e}$ 22a Regional de Saúde (RS). Nesta macrorregião $84,5 \%$ dos municípios são classificados como de pequeno porte e no Paraná, dos 399 municípios, $312(78,1 \%)$ são MPP.

Foram selecionados 55 representantes das equipes gestoras que se destacaram no desenvolvimento das atividades de gestão, obtidos por uma amostra de conveniência de cada RS, identificados a partir de entrevistas com informanteschave das regionais de saúde. A coleta de dados ocorreu por meio de cinco grupos operativos, um em cada RS, do qual participaram os selecionados, variando entre 10 e 18 pessoas por região, durante o período de abril a junho de 2015. Os grupos foram conduzidos a partir de um roteiro contendo questões que versavam sobre os tipos de problema presentes nos municípios e as estratégias de gestão utilizadas para o enfrentamento destes.

Do material empírico produzido foi realizada análise compreensiva e interpretativa. Primeiramente, foi realizada leitura horizontal e exaustiva dos textos produzidos. Esse exercício inicial, também chamado de "leitura flutuante", permitiu apreender as ideias centrais dos atores sociais, os momentos-chave e suas posturas sobre o tema ${ }^{19}$. Em um segundo momento, foi realizada a leitura transversal do material, identificadas as unidades de sentidos, buscando perceber as conexões entre $\operatorname{essas}^{20}$.

Após essa fase, num segundo momento, foi feita a síntese desta classificação, agrupando-as 


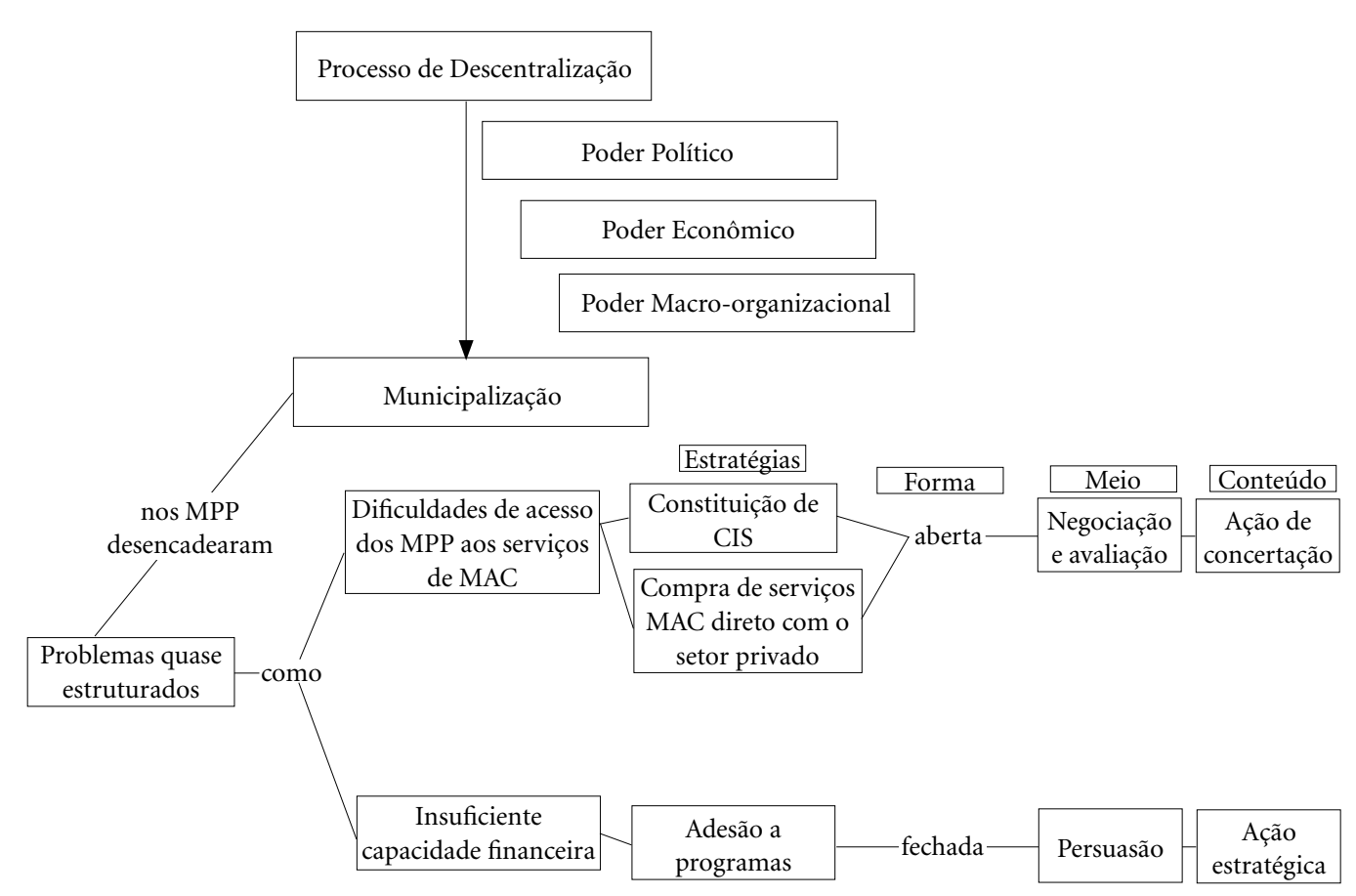

Figura 1. Problemas e estratégias de gestão do SUS em MPP.

em categorias empíricas, buscando compreender e interpretar o que foi mais relevante $e^{20}$. A análise foi realizada à luz do referencial teórico do jogo social de Carlos Matus.

Para a garantia do anonimato dos participantes, as falas foram codificadas por letras do alfabeto e por números. Primeiramente, os grupos foram denominados pela letra " $G$ ", e em seguida pela letra inicial da regional a que pertencia (A, C, L, J, I) e conforme as falas foram surgindo, foram designados por números sequenciais $(1,2$, $3,4 \ldots)$.

Este estudo faz parte de um projeto maior "A gestão do trabalho no SUS em Municípios de Pequeno Porte do Paraná a partir do olhar da equipe gestora”. A pesquisa respeitou as normas relativas a pesquisas que envolvem seres humanos, conforme Resolução ${ }^{\circ}$ 466/2012 ${ }^{21}$ do Conselho Nacional de Saúde e foi submetida e aprovada pelo Comitê de Ética em Pesquisa da Universidade a que estão filiados os pesquisadores, em 14/09/2012.

\section{Resultados e discussão}

A apresentação dos resultados dos grupos operativos está organizada em duas categorias empíricas: uma relacionada aos problemas e a outra às estratégias (Figura 1). Na primeira categoria foram analisados dois problemas e na segunda três estratégias.

\section{Problemas}

A descentralização da gestão do SUS foi o principal caminho para a viabilização da universalidade do sistema. A forma como ela se processou para o ente municipal, chamada de "municipalização", foi problemática pois não proporcionou o compartilhamento de funções e competências de gestão do sistema entre os entes federados ${ }^{22}$. Deste modo, houve uma acentuada atribuição aos municípios no que se refere à provisão técnica de ações e serviços de saúde em seu território ${ }^{23}$, fato que evidenciou a condição de vulnerabilidade, sobretudo, dos pequenos municípios. 
Um problema relevante mencionado pela equipe gestora refere-se à dificuldade de garantir acesso de seus munícipes aos serviços da MAC. Tendo em vista a inexistência de oferta destes serviços nos MPP, destacaram o desafio referente à compra de serviços desta modalidade. Se o município quer resolver, ele acaba pagando, senão a fila de cirurgia não anda (GC5). Ortopedia é um caos, nem com ação judicial, o consórcio faz um convênio com o hospital B na cidade D, mas quem paga esse convênio é o município (GA2).

As condições para que a descentralização atendesse a garantia do acesso e da atenção integral, de acordo com as necessidades da população, não foram asseguradas, sobretudo, porque não se considerou a diversidade da realidade dos municípios brasileiros ${ }^{2,24}$. A forma como se processou a descentralização, com grande enfase para a municipalização, provocou a criação de vários sistemas locais isolados, enquanto que na área da MAC verifica-se a fragmentação e a desorganização dos serviços de saúde. Para a autora isso ocorre porque os espaços decisórios dos gestores são permeados por interesses locais, em detrimento da garantia de acesso universal ${ }^{25}$.

Para Silva et al. ${ }^{13}$, um fator que contribui para que o problema do acesso a serviços especializados em MPP não vislumbre solução a curto prazo, é que os mecanismos legais, como o Contrato Organizativo da Ação Pública (COAP), propostos para viabilizar a organização e a oferta das ações e serviços de MAC na região não se efetivou. Segundo os autores, isso se deve ao crescente distanciamento das instâncias Federal e Estadual de suas atribuições, tanto no que diz respeito ao financiamento quanto à gestão do sistema.

$\mathrm{Na}$ tentativa de garantir acesso à atenção especializada, os gestores de MPP têm assumido o desenvolvimento de ações da MAC que extrapolam aquelas pactuadas pelos mesmos e, em consequência disto, têm investido mais do que preconiza a Lei 141/2012 para os gastos com saú$\mathrm{de}^{13}$. Estes mesmos autores apontam que no ano de 2014, nos MPP de uma região do Paraná, a média de gastos com recursos próprios para as despesas em saúde, em relação ao gasto total deste segmento, correspondeu em média $69,7 \%$, variando entre $57,2 \%$ e $81,8 \%{ }^{13}$. O alto percentual de recursos do orçamento municipal investidos em saúde demonstra o grande peso de responsabilização que recai sobre os municípios.

Pelo exposto, verifica-se que o ganho de autonomia dos municípios também foi acompanhado de aumento da responsabilidade pelo financiamento das ações e serviços de saúde. Essa situação pode ser ilustrada ao analisar o crescimento das despesas públicas com saúde no período compreendido entre 2008 e 2015 , em que as despesas dos Governos Federal e estaduais cresceram $40,4 \%$ e $49,4 \%$ respectivamente, enquanto os municípios aumentaram suas despesas com saúde em $71,6 \%{ }^{26}$.

Ao analisar o jogo social ${ }^{14}$ presente no problema analisado, é possível inferir que os poderes macro-organizacional, político e econômico foram exercidos pelo ente federal sobre os municípios.

O poder macro-organizacional denotou-se pela forma como foi organizado o processo de descentralização, em que a União, exercendo um poder embasado em recursos burocráticos e institucionais, produziu a transferência aos municipios de uma maior responsabilidade sobre a gestão e a assistência à saúde em seu território ${ }^{14}$, ainda que os MPP não dispusessem de condições para responder às demandas por atenção integral aos seus munícipes.

Pela perspetiva de Matus ${ }^{14}$, essa situação poderia ser considerada um problema quase estruturado. Esta tipologia de problema, mesmo que tenha uma dimensão técnica, sempre abrange a esfera sociopolítica e torna-se um desafio múltiplo, devido ao fato da solução dada ao problema, neste caso - a compra de serviços de MAC -, gerar outro problema - a sobrecarga financeira e de responsabilidades ao MPP -, que estão conexos, pois o sistema é contínuo.

Corroborando tal afirmação, os participantes do estudo destacaram a insuficiente capacidade financeira como outro problema nos MPP: A demanda aumentou demais, tudo sem planejamento, porque ninguém se planejou (GC8). Por não contar com uma estrutra de serviço, com capacidade de ofertar assistência integral aos munícipes, as despesas dos MPP tiveram um aumento considerável ... o que a gente recebe de outros entes é muito pouco, vai depender do per capita de cada município(GI2); Tudo a gente paga (GA8); O município arca com tudo (GC4).

Conforme já mencionado, a descentralização foi regida por um caráter de desconcentração do poder, em que se designou um poder político ${ }^{14}$ maior aos municípios, atrelado a uma autonomia na condução das ações em saúde. Entretanto, exigiu maior dispêndio de recursos financeiros pelo município, acompanhado de uma contenção de gastos por parte da União.

Arretche e Marques ${ }^{27}$, apontam que a sobrecarga financeira vivenciada pelos municipios decorre da descentralização das ações assumidas, 
principalmente ambulatoriais, as que mais ampliaram os gastos em saúde para estes entes.

Os MPP, quando comparados aos municipios de médio e grande porte, apresentam características muito peculiares, pois em geral são situados em regiões geográficas mais isoladas, com situações de maior vulnerabilidade social e econômica ${ }^{28}$.

Calvo et al. ${ }^{29}$ realizaram estudo que avaliava a presença de categorias favoráveis à gestão em saúde, relacionadas às caracteristicas demográficas, capacidade de financiamento e poder aquisitivo da população. Os resultados revelaram um importante contraste entre os municípios de grande e pequeno porte. Enquanto de 77 a 100\% dos municípios de grande porte apresentavam aspectos favoráveis para a gestão em saúde, apenas de 10 a 17\% dos municípios de pequeno porte possuiam tais aspectos.

Autores afirmam que prevaleceu nesse processo de descentralização o caráter estratégico de intervenção na economia, com o enxugamento do Estado e a estabilidade econômica em que, ao transferir responsabilidade aos entes municipais, não foi priorizada a garantia de acesso universal dos usuários aos serviços de saúde. Dessa forma, a descentralização do sistema de saúde serviu mais ao propósito de retração da União e de contenção de despesas do que de sua expansão. Ou seja, a municipalização representou uma estratégia de deslocamento da responsabilidade sobre o gasto social para as esferas subnacionais, que em geral não têm condições de assumir tais encargos $^{2,30}$. Neste contexto, destaca-se o uso dos poderes político e econômico ${ }^{14}$.

\section{Estratégias}

Esta seção tem o objetivo de analisar as estratégias de gestão utilizadas pela equipe gestora para o enfrentamento dos problemas relacionados à dificuldade de garantir acesso aos serviços da MAC e à inuficiente capacidade financeira dos MPP.

Nas regiões estudadas a estratégia utilizada por todos os municípios para proporcionar o acesso à atenção de MAC foi a constituição de Consórcios Intermunicipais de Saúde (CIS). Esta foi a forma de administrar e prover, à população dos municípios consorciados, serviços especializados e de apoio diagnóstico de maior densidade tecnológica.

Segundo os entrevistados, ao se consorciar, o município contribui com um valor per capita mensal, para utilizar os serviços do CIS, com isso têm acesso a um número estipulado de consul- tas e exames mensais. Caso seja necessário, há a possibilidade de ampliar a compra de exames e consultas, sendo cobrado um valor extra, denominado de "extra cota".

Os resultados deste estudo corroboram o apontado por diversos autores, de que os CIS se constituem em uma estratégia potencializadora do acesso à assistência médica especializada, de serviços de MAC, e como um dos instrumentos de regionalização da gestão do SUS ${ }^{31-33}$.

No Estado do Paraná, os consórcios públicos são exclusivamente intermunicipais, autônomos, para gerir sobre as políticas regionais no âmbito da ação, e os interesses coletivos são deliberados por conselhos de prefeitos ${ }^{33}$.

Nas regiões estudadas os CIS existentes procuram realizar a contratação de serviços junto ao setor privado negociando as ações e os serviços por meio de um aditivo à tabela SUS, na tentativa de conseguir comprar os serviços necessários. No entanto, nem sempre os valores propostos atendem o interesse do setor privado, ou seja, nem sempre há adesão ao valor proposto pelo CIS, o que ocasiona dificuldades relacionadas à contratação de serviços e de profissionais especialistas para a oferta aos municípios.

Verificou-se também que a situação dos consórcios não é uniforme nas regiões estudadas. Em algumas regiões, segundo o relato dos gestores, os CIS acabam exercendo a mera função de intermediar a contratação de serviços de MAC junto ao setor privado, e não conseguem exercer um papel que vai além da compra de serviços. Desta forma, não alcançam a integração da assistência entre os diversos pontos de atenção, resultando em oferta insuficiente ou mesmo inexistência de oferta em algumas áreas. A não efetividade do consórcio nestas regiões reflete os enfrentamentos e as debilidades quanto aos serviços de MAC e repercute diretamente na qualidade e continuidade da assistência à saúde aos munícipes.

Esta situação faz com que muitos gestores tenham que se utilizar de outra estratégia, a compra de ações e serviços de saúde de MAC diretamente do setor privado complementar;

Faz convênio com clínicas particulares (GL5); Na clínica Y paga consulta, exames (GA3);

Tem a clínica $X$ que eu pago consultas quando não consegue pelo consórcio, ou é urgente e não consegue resolver, lá também faz colonoscopia, endoscopia, ultrassonografia endovaginal (GC3).

Observa-se que o município acaba arcando com atribuições e recursos financeiros para suprir as necessidades dos usuários que vão além da $\mathrm{AB}$, na tentativa de proporcionar o acesso aos 
serviços de saúde, e desta forma, acaba gastando o seu recurso de atenção básica pra resolver média e alta complexidade (GJ1).

A equipe gestora tenta enfrentar o problema, na prática, a partir de operações planejadas como a utilização de seu poder econômico, pois possui o domínio do seu orçamento. Na tentativa de suprir suas necessidades, remaneja o orçamento municipal com um dispêndio maior de recursos para a área da saúde, e dentro desta acaba destinando maior recurso para as demandas de MAC, que não estão organizadas na região e que oferecem maior dificuldade de resolução, pelo município. Neste sentido, as ações da $\mathrm{AB}$ acabam não tendo o investimento que deveriam, ou que possibilitasse uma mudança no panorama dos serviços desse nível de atenção.

Ao analisar os motivos do município utilizar o recurso próprio como forma de intervir neste problema, Mendes ${ }^{34}$ aponta que, apesar de existirem mecanismos de alocação equitativa de recursos das transferências do governo federal para os municípios, pela Lei 141/2012, ainda não se conseguiu definir critérios baseados em necessidades de saúde, além de existir uma participação muito incipiente dos governos estaduais na transferência de recursos para os municípios.

Em relação à compra de serviços da MAC, verifica-se que essa estratégia não tem sido adotada de forma a complementar à $\mathrm{AB}$, nem mesmo para aumentar a resolutividade deste nível de atenção. Pelo contrário, são ações pontuais, isoladas, e que muitas vezes refletem uma relação de clientelismo entre a população usuária e o gestor, pois o cidadão, ele mora no município, então ele conhece todo o mundo, o secretário, o prefeito, e ele vai bater na porta da sua casa. (GJ1).

Esta estratégia também denota a dependência do município ao setor privado que, na maioria das vezes, não tem vínculo ou corresponsabilização pela continuidade do cuidado, integralidade e resolutividade e, ao invés de promover mudança, acaba por reforçar o modelo de atenção biomédico, ainda hegemônico. Verifica-se que na relação entre gestores públicos e prestadores privados em MPP, prevalece assimetrias de poder, interesses e benefícios, além de práticas clientelistas e hierarquizadas 5 .

Nesse tipo de estratégia, uma relação de troca ou permuta de problemas encontra-se mascarada. O problema, que anteriormente era a insuficiente oferta de serviços da MAC, acaba cedendo lugar à baixa eficácia da estratégia adotada, tendo em vista a pouca resolutividade dessas ações ou o aumento dos gastos para o município, o que também reflete na reprodução do modelo biomédico de atenção à saúde. Neste sentido, todo intercâmbio de problemas é conflituoso, pois se refere a valores que são diferenciados de acordo com cada problema, que pode ser intensificado ou mitigado.

Verifica-se que a equipe gestora utiliza-se de estratégias que em sua forma ou administração são consideradas abertas, isto é, existe uma descentralização das decisões para seu cumprimento, deixando amplo espaço de liberdade para o uso da criatividade e da informação do momento $^{14}$. Ou seja, se naquela oportunidade ou momento é viável realizar convênio com uma clínica, o município irá aderir a essa estratégia; caso não seja possível, a alternativa será descartada. Neste sentido, existe uma abertura para a equipe gestora tomar esta decisão, que vai de acordo com a circunstância requerida no momento.

Ao analisar as vias estratégicas empregáveis, verifica-se que na maioria das vezes a equipe gestora utiliza-se da avaliação e da negociação para encontrar os meios ou vias de se obter um resultado positivo. Neste intuito, o gestor inicialmente avalia a situação, analisando as formas de intervir, e depois tenta negociar como utilizar os serviços contratados para que possa proporcionar determinado tipo de cuidado ao usuário.

Quanto ao seu conteúdo, as estratégias utilizadas enquadram-se na ação de concertação na qual o propósito e a motivação dos atores estão relacionados com a comunidade ${ }^{14}$. Neste sentido, a equipe gestora se esforça na medida do possível para proporcionar a garantia do acesso aos serviços de saúde.

Diante destas estratégias e táticas de jogo, percebe-se que o jogo econômico continua sendo o tipo de poder que se sobressai nas situações apresentadas e detém o domínio sobre os outros tipos de jogos.

Para o enfrentamento dos problemas referente à insuficiente capacidade financeira, a equipe gestora refereriu a adesão a programas oferecidos pelo estado e pela União. A adesão ao Programa Mais Médicos (PMM) foi referida por grande parte dos municípios na tentativa de resolver a dificuldade de fixar os médicos em seus territórios bem como custear os salários desses profissionais. Pelo programa, os encargos dos médicos eram custeados pelo governo federal, fato que aliviava, em alguma medida, o orçamento dos pequenos municipios.

A adesão a outros programas também foi apontada pela equipe gestora para ampliar os recursos financeiros transferidos dos outros en- 
tes para o município e assim proporcionar melhoria dos serviços de saúde: Estratégia de Saúde da Família, o Programa de Melhoria do Acesso e da Qualidade da Atenção Básica (PMAQ-AB), o Programa de Qualificação da Vigilância em Saúde (VIGIASUS), o Programa de Apoio e Qualificação dos Hospitais Públicos e Filantrópicos do SUS (HOSPSUS), o Programa de Qualificação da Atenção Primária no SUS (APSUS), e a adesão às redes de atenção à saúde.

O APSUS foi destacado pela equipe como disparador de mudanças no processo de trabalho dos serviços, principalmente pelas ações de educação permanente em saúde (EPS), que proporcionaram melhoria no atendimento dos serviços como um todo. Alguns municípios destacaram o HOSPSUS na execução da contratualização ou pactuação com alguns hospitais por meio de fluxos de referência, que facilitaram a entrada e o atendimento do usuário na atenção hospitalar.

Os beneficios trazidos pelo APSUS e HOSPSUS, as quais constituem estratégias estaduais, ainda que tenham uma forma de administração fechada, são estratégias com conteúdo que conformam uma ação de concertação, que tiveram um propósito de melhoria da atenção em saúde ${ }^{14}$.

Mesmo tendo aderido a tais programas como forma de obter recursos para melhorar o atendimento da população, para alguns municípios de uma região de saúde, a equipe gestora referiu que a União e o Estado utilizam o incentivo de recursos financeiros oriundo desses programas como forma de atrair o município para a adesão aos mesmos.

São iscas, eles colocam estes programas como iscas para a gente querer o programa e cair na ilusão de que tudo vai melhorar. Eles oferecem o programa e um incentivo para a gente, oferecem dinheiro (GI1);

$\mathrm{Na}$ realidade esse incentivo não paga nem metade do custo do programa, aí eles querem que o município caia na deles, mas o município acaba tendo que arcar com o restante das despesas, porque na verdade o dinheiro que é repassado não cobre as despesas dos programas (GI8).

Diante disso, os municípios deparam-se novamente com a situação de que a adesão a um programa que auxilia no enfrentamento de um problema, acaba gerando um outro que está relacionado ao gasto para manutenção dessa estratégia.

Pela situação apresentada, os programas federais tornam-se estratégias da União com característica fechada, pois já chega pronta para o município e este deve executá-la da forma como foi pensada, caracterizando uma ação estratégica para cumprir um interesse da União e não uma ação de concertação para atender as necessidades da atenção em saúde. A execução de uma estratégia constitui uma jogada, devendo o ator levar em conta que o jogo social combina ações diretas e transparentes com outras disfarçadas; ou seja, existe a possibilidade de um duplo jogo ${ }^{14}$.

Os poderes político e econômico podem ser vistos na disputa pelo controle do sistema de saúde, no qual o ente federal, detentor do maior volume de recursos, induz financeiramente a adesão aos programas e estratégias pelos municípios.

\section{Considerações finais}

Tendo como base as análises dos problemas e estratégias de gestão que emergiram da compreensão sobre a dinâmica da gestão do SUS em MPP, destaca-se que o principal desafio dos gestores é o de fazer que o SUS, proposto pela constituinte, aconteça na realidade dos serviços de saúde, com mudanças no modelo de atenção. Este desafio torna-se maior para os MPP, considerando que, diferente dos municípios de médio e grande porte, aliam menor capacidade técnica da equipe gestora, menor densidade demográfica e poder aquisitivo da população e ainda insuficiente capacidade de financiamento para responder aos desafios de gerir o sistema de saúde.

Por mais que existam algumas diretrizes como alicerce para a mudança do modelo de atenção, o modelo biomédico é tão hegemônico que os gestores, ao enfrentarem os problemas da gestão, não conseguem realizar outros tipos de ação ou estratégias que não sejam para ampliar a oferta de serviços. Entretanto, reconhecem que tais ações são insuficientes para garantir um caminho efetivo como via permanente; os problemas são reconhecidos, porém as estratégias adotadas (consórcios, compras de serviços, adesão a programas) não são potentes para a resolução dos mesmos.

A descentralização da forma como foi desencadeada deixou os MPP em situação de maior vulnerabilidade perante os demais entes, especialmente a vulnerabilidade financeira. Os poderes macro-organizacional e econômico foram predominantes para o desencadeamento dos problemas.

As estratégias adotadas para o enfrentamento dos problemas acabam desencadeando outros, $\mathrm{o}$ que Matus denomina de intercâmbio de problemas, e acabam por aumentar a vulnerabilidade dos MPP. Diante destas estratégias e táticas de 
jogo, percebe-se que o jogo econômico continua sendo o tipo de poder que se sobressai nas situações apresentadas e que possui o domínio dos outros tipos de jogos submissos a ele.

A Emenda Constitucional 95, aprovada em 2016, que congela os gastos da União em saúde por um período de 20 anos e estabelece limites desfavoráveis de correção no financiamento deste mesmo setor ${ }^{35}$, compromete ainda mais a capacidade da esfera municipal em gerir as políticas públicas locais de forma eficiente. Assim, é ainda mais necessário reorganizar o processo de descentralização, para que o ente estadual assuma uma posição de coordenação efetiva e coparticipação na constituição das redes e no processo de regionalização, com financiamento condizente.

Também é preciso fomentar o empoderamento do gestor municipal, ou seja, ampliar suas forças, política e social, por meio do fortalecimento de suas capacidades. Para tanto é fundamental a implantação de processos de escuta das necessidades dos municípios menores nos espaços de governança regional, a criação de uma cultura de enfrentamento dos problemas de forma coletiva e compartilhada entre os entes federados, promovendo assim a gestão interfederativa. Neste sentido, as Comissões Intergestores Regionais e as Comissões Intergestores Bipartites devem criar espaços de discussões ou grupos de trabalho para a construção de práticas efetivas e que auxiliem os MPP a superarem seus problemas.

Tal mobilização inclui a união de forças de todos os gestores, trabalhadores de saúde, da sociedade organizada e da população para defender o sistema público de saúde, que em seus mais de trinta anos de existência ainda não conseguiu se concretizar devido aos golpes sofridos para seu desmonte.

\section{Colaboradores}

Todos os autores participaram diretamente no planejamento, execução ou análises desse estudo, conforme descrição abaixo: Os autores E Pinafo, EFPA Nunes, BG Carvalho, FF Mendonça e CM Domingos participaram, igualmente, da elaboração do manuscrito, de sua discussão e redação e da revisão do texto. CR Silva colaborou na discussão e revisão final do texto. Todos os autores leram e aprovaram a versão final enviada.

\section{Referências}

1. Leite FBL. Fusão de Municípios: Impactos econômicos e políticos da diminuição do número de municípios em Minas Gerais [dissertação]. Braga: Universidade do Minho; 2014.

2. Lima LD, Viana ALD, Machado CV. Regionalização da saúde no Brasil: Condicionantes de Desafios. In: Scatena JHG, Kehrig RT, Spinelli MAS, organizadores. Regiões de Saúde, diversidade e processo de regionalização em Mato Grosso. São Paulo: Editora Hucitec; 2014. p. 21-46.

3. Pinafo E, Carvalho BG, Nunes EFPA. Descentralização da gestão: caminho percorrido, nós críticos e perspectivas. Cien Saude Colet 2016; 21(5):1511-1524.

4. Sistema de Informações sobre Orçamentos Públicos em Saúde. Despesas em Saúde Região Macronorte do Estado do Paraná, 2014. [acessado 2015 ago 10]. Disponível em: http://portalsaude.saude.gov.br.

5. Silva JFM, Carvalho BG, Domingos CM. A governança e a relação público-privado no cotidiano das práticas em municípios de pequeno porte. Cien Saude Colet 2018; 23(10):3179-3188. 
6. Scheffer M. Demografia Médica no Brasil 2015. São Paulo: USP, Conselho Regional de Medicina do Estado de São Paulo, Conselho Federal de Medicina; 2015.

7. Machado CV, Lima LD, Baptista TWF. Princípios organizativos e instâncias de gestão do SUS. In: Gondim R, Gabrois V, Mendes W, organizadores. Qualificação de gestores no SUS. Rio de Janeiro: EAD/Ensp; 2011. p. 47-72.

8. Villani RAG, Bezerra AFB. Concepções dos gestores municipais de saúde de Pernambuco sobre a destinação e gestão dos gastos com saúde. Saúde Soc 2013; 22(2):521-529.

9. Mello GA, Ibañez N, Viana ALd'A. Um olhar histórico sobre a questão regional e os serviços básicos de saúde no Estado de São Paulo. Saúde Soc. 2011; 20(4):853866.

10. Leite VR, Lima KC, Vasconcelos CM. Financiamento, gasto público e gestão dos recursos em saúde: o cenário de um estado brasileiro. Cien Saude Colet 2012; 17(7):1849-1856.

11. Teixeira L, Mc Dowel MC, Bugarin M. Consórcios Intermunicipais de Saúde: Uma análise à luz da Teoria dos Jogos. Rev. Bras. Econ. 2003; 57(1):253-281.

12. Pinafo E. Problemas e estratégias de gestão do SUS em municípios de pequeno porte [tese]. Londrina: Universidade Estadual de Londrina; 2017.

13. Silva CR, Carvalho BG, Cordoni Junior L, Nunes EFPA. Dificuldade de acesso a serviços de média complexidade em municípios de pequeno porte: um estudo de caso. Cien Saude Colet 2017; 22(4):1109-1120.

14. Matus C. Teoria do jogo social. São Paulo: FUNDAP; 2005.

15. Matus C. Estrategia y Plan. $2^{\text {a }}$ ed. México: Siglo XXI; 1978.

16. Giovanella L. Ideologia e poder no planejamento estratégico em saúde: uma discussão da abordagem de Mario Testa [dissertação]. Rio de Janeiro: Escola Nacional de Saúde Pública, Fundação Oswaldo Cruz; 1989.

17. Lima JC. Fundação Oswaldo Cruz. Resenhas Book Reviews. Matus C. Teoria do jogo social. Cien Saude Colet 2010; 15(5):sp.

18. Artmann E. Interdisciplinaridade no enfoque intersubjetivo habermasiano: reflexões sobre o planejamento e AIDS. Cien Saude Colet 2001; 6(1):183-195.

19. Minayo MCS. O desafio do conhecimento: pesquisa qualitativa em saúde. 12a ed. São Paulo: Hucitec; 2010.

20. Minayo MCS. O desafio do Conhecimento: pesquisa qualitativa e saúde. 11 $1^{\mathrm{a}}$ ed. São Paulo: Hucitec; 2008.

21. Brasil. Ministério da Saúde (MS). Diretrizes e normas regulamentadoras de pesquisas envolvendo seres $h u$ manos: (Res. CNS 466). Brasília: MS; 2012.

22. Pasche DF, Righi LB, Thomé HI, Stolz ED. Paradoxos das políticas de descentralização de saúde no Brasil. Rev. Panam. Salud Publica 2006; 20(6):416-422.

23. Lima LD, Viana ALd`A, Machado, CV, Albuquerque MV, Oliveira RG, Iozzi FL, Scatena JHG, Mello GA, Pereira AMM, Coelho APS. Regionalização e acesso à saúde nos estados brasileiros: condicionantes históricos e político-institucionais. Cien Saude Colet 2012; 17(11):2881-2892.
24. Viana AlD’A, Lima LD. O processo de regionalização na saúde: contextos, condicionantes e papel das Comissões Intergestores Bipartites. In: Viana AlD’A, Lima LD organizadores. Regionalização e relações federativas na política de saúde do Brasil. Rio de Janeiro: Contracapa; 2011. p. 11-24.

25. Viana ALD. SUS além dos limites territoriais (entrevista). Revista Região e Redes - Caminho para a universalização da saúde no Brasil. 2014. [acessado 2015 Jul 5]. Disponível em: http://www.resbr.net.br/o-susalem-dos-limites-territoriais

26. Mendes EV. A descentralização do sistema de serviços de saúde no Brasil: novos rumos e um novo olhar sobre o nível local. In: Mendes EV, organizador. A organização da saúde no nível local. São Paulo: Hucitec; 1998. p. 17-75.

27. Arretche M, Marques E. Condicionantes locais da descentralização as políticas de saúde. In: Hochman G, Arretche M, Marques E, organizadores. Políticas Públicas no Brasil. Rio de Janeiro: Editora Fiocruz; 2007. p. 173-204.

28. Cordoni Júnior L. Prefácio. In: Carvalho BG, Nunes EFPA, Cordoni Júnior L, organizadores. Gestão da Saúde em pequenos municipios: $O$ caso do norte do Paraná. Londrina: Eduel; 2018. p.11-13

29. Calvo MCM, Lacerda JT, Colussi CF, Schneider IJC, Rocha TAH. Estratificação de municípios brasileiros para avaliação de desempenho em saúde. Epidemiol. Serv. Saúde 2016; 25(4):767-776.

30. Lima LD. Federalismo fiscal e financiamento descentralizado do SUS: balanço de uma década expandida. Trab. educ. saúde 2008; 6(3):573-598.

31. Quandt FL. Avaliação da efetividade do Consórcio Intermunicipal de Saúde na região do Alto Uruguai Catarinense - CIS/AMAUC [dissertação]. Florianópolis: Universidade Federal de Santa Catarina; 2012.

32. Nicoletto SCS, Cordoni JL, Costa NR. Consórcios Intermunicipais de Saúde: o caso do Paraná, Brasil. Cad Saude Publica 2005; 21(1):29-38.

33. Andrade SKAV. Atuação dos gestores de saúde no âmbito da relação federativa e da ação consorciada [dissertação]. Londrina: Universidade Estadual de Londrina; 2018.

34. Mendes EV. O processo de construção da gestão regional da saúde no estado de São Paulo: subsídios para a análise. Saúde Soc 2015; 24(2):423-437.

35. Brasil. Emenda Constitucional no 95 , de 15 de dezembro de 2016. Altera o ato de disposições constitucionais transitórias, para instituir o novo regime fiscal, e dá outras providências. Diário Oficial da União 2016; 15 dez.

Artigo apresentado em 30/05/2019

Aprovado em 07/08/2019

Versão final apresentada em 27/11/2019 